\title{
Information Processing Correlates of Reading
}

\author{
JOHN PALMER \\ University of Michigan \\ COLIN M. MACLEOD \\ University of Toronto. Scarborough Campus \\ EARL HUNT \\ University of Washington \\ AND \\ JANET E. DAVIDSON \\ Yale University
}

\begin{abstract}
Individual differences in reading correlate with individual differences in perception. in memory, and in other simple processes. This study measured these relationships using information processing tasks such as visual search. visual matching, and span of apprehensjon; and using linguistic processing tasks such as word-nonword judgment, picture-sentence verification, and semantic categorization. These tasks were performed by a large sample of college students chosen to represent the full range of college-level reading ability. Three salient findings emerged: (a) Reading correlates with the information processing measures when they involve words, but it does not correlate with otherwise identical measures involving letters. (b) Reading speed and comprehension have different correlations with the information processing measures, although they have similar correlations with the linguistic processing measures. (c) Reading speed is only moderately correlated with listening comprehension, but reading comprehension ability is indistinguishable from listening comprehension ability. These results indicate that reading speed and comprehension depend on abilities that are at least partly distinct. Specifieally, reading speed varies with visual word processing, while reading comprehension varies with nonvisual linguistic processing.

14k5 Academic Press, Inc.
\end{abstract}

This research was supported by National Institute of Education Grant G77-0012 to the University of Washington. Preparation of the paper was supported by Grant A7459 from Natural Sciences and Engineering Research Council of Canada, We are grateful to the following people for their contributions: Steven Poltrock for early contributions to the ideas; Susan Chipman. John Jonides. John Kounios. Marcy Lansman. David Meyer, Steve Yantis, Zclda Zabinsky, and anonymous reviewers for critical comments on earlier drafts; Joy Taylor for compiling the reading speed test; and Colene McKee for assistance with programming and data analysis. We also thank bavid Meyer for providing his materials for the lexical decision task, and Frank Andrews for statistical ad$\checkmark$ ice. Requests for reprints may be sent to Earl Hunt. Department of Psychology, NI-25, University of Washington. Seattle. Wash. 98195.
There are wide individual differences in the reading skills of college students. For example, Perfetti (1984) estimates differences in reading speed of as much as 4 to 1 and similar differences in comprehension. To account for these individual differences, one can consider variation in three classes of processes: (a) processes analyzing the visual aspects of individual words and sentences, (b) processes integrating information presented at different points in a text, and (c) processes relating information in a text to general world knowledge (Frederiksen, 1982). This paper is concerned with the first class, that of elementary informa- 
tion handling processes. There are considerable individual differences in people's ability to deal with isolated lexical items and in their ability to deal with simple, isolated sentences (Hunt, 1978). How do these individual differences relate to reading skill?

To investigate this relationship, we had university undergraduates participate in a variety of tasks involving reading as well as selected aspects of perception and of memory for letters. letter strings, and words. The perception and memory tasks were considered in two groups. One group of tasks treated the stimuli as visual units or as visual symbols with a phonological code, but without regard to meaning. The other group of tasks required comprehending the meaning of the stimulus units. The motivation for these groupings was that the processing of a visual stimulus as a lexical unit is unique to reading, while tasks involving the processing of meaning should be related to language comprehension more generally. We hypothesized that these processes are potentially distinct sources of individual differences in reading skill.

\section{Background}

There is an extensive literature on nomothetic studies of reading and on the abilities of developing or disabled readers (see reviews by Smith \& Spoehr, 1974; Gibson \& Levin, 1975). Furthermore, there is a growing literature on how individual differences in particular laboratory tasks are related to reading ability (cf. Calfee, 1977; Carr, 1981; Carroll \& Maxwell, 1979; Perfetti \& Lesgold, 1978). Yet, there are only a few studies measuring the relative roles of elementary information processing abilities as compared to more complex abilities. Two such studies are relevant.

Jackson and McClelland (1975, 1979) studied reading skill in university students using a variety of elementary information processing tasks. Most important was a set of related matching tasks that depended on five different kinds of information: the physical identity of nonlinguistic visual patterns, the physical identity of letters, the name identity of letters, the sound of words, and the meaning of words. In addition, Jackson and McClelland (1979) measured listening comprehension as well as reading comprehension and reading speed. The addition of a listening measure allowed them to address the relationship between reading ability and both general comprehension and elementary processing abilities.

Jackson and McClelland first defined reading skill as a combination of reading speed and comprehension. This measure has the advantage of considering both speed and accuracy, but the disadvantage of combining possibly different aspects of reading without an explicit theoretical basis (cf. Blommers \& Lindquist, 1944; McConkie, Rayner, \& Wilson, 1973). Next, they considered which of their measures best predicted reading skill. The listening comprehension measure showed the largest correlations $(r=.7)$ and the linguisticstimuli matching tasks also produced significant correlations $(r=.3$ to .5$)$. When combined in a multiple regression analysis, the best predictors of reading ability were listening comprehension and letter-name matching. Given these correlations, and the result that the nonlinguistic matching tasks were not related to reading. Jackson and McClelland concluded that letter decoding and general comprehension are important components of reading. In other words, the relevant elementary information processing ability in reading is the ability to access the representation of a learned symbol. be it a letter or a word.

Jackson and McClelland acknowledged several limits on their conclusion. By using a small sample constructed from extreme groups, they almost certainly overstated the relations between their measures. For example, their data show the relationship between listening and reading comprehension growing from about $r=.6$ for their whole sample to about $r=.7$ for their ex- 
treme group sample. In terms of variance accounted for $\left(r^{2}\right)$, this is an increase from .36 to .49 , a $36 \%$ inflation. Their use of a composite comprehension and speed measure also raises a problem. The speed measure was more reliable than the comprehension measure $(r=.82$ as compared with $r=$ $.55)$ and thus may have dominated the composite. Further, as is often done, Jackson and McClelland relied on one task (matching) to measure each of the presumed elementary processes. Without additional converging evidence. a considerable burden is placed on the accuracy of our theoretical interpretation of that one task. Despite these difficulties, Jackson and McClelland's work stands out for its methodical comparisons of the related matching tasks.

More recently, Frederiksen (1980, 1982) reported a series of studies relating reading and information processing ability in a sample of high school graduates whose reading abilities covered the normal adult range. He included measures of all three classes of information processing mentioned earlier: processes dealing with words and isolated sentences, processes dealing with the integration of information across the text, and processes dealing with the meaning of the text in the context of background information. For example, he measured elementary processes both with familiar measures of matching and search and with more novel measures. These novel measures included: bigram frequency effects in a modified span-of-apprehension lask, vowel and syllable complexity effects in pseudoword vocalization, and frequency effects in word vocalization. Frederiksen found several significant relationships between reading and the processing lasks. Of particular interest here, he found reading ability to be predicted by tasks that depended on recognizing words and symbolname correspondences. This is quite consistent with Jackson and McClelland's conclusion.

Frederiksen's studies are powerful in two senses: through his use of a wide range of adult reading abilities and through his use of a powerful statistical technique (Analysis of Covariance Structures, Jöreskog \& Sörbom, 1978). However, for our purposes, his studies also are limited. He used elementary processing measures that were for the most part unique to his work, rather than adapting measures that had been the subject of intensive study. Because of this, it is difficult to relate his definition of, say, phonological recoding to the use of the same term in other studies. 'l hus, the question remains: To what extent are individual differences in comprehension and speed dependent on variation in more elementary processes?

\section{The Current Study}

Our study builds on the work of Frederiksen and of Jackson and McClelland in several ways. Following Frederiksen, we have used multiple measures for each assumed underlying ability, and have analyzed the data from a sample intentionally constructed to mirror the range of reading ability in a definable class of people, college students, Following Jackson and McClelland, we aim to relate individual differences in reading skill to individual differences in performing a number of previously well investigated experimental paradigms. The paradigms themselves can be divided into those requiring a response to visual or name properties of a stimulus (e.g., letter matching), and those requiring a response to the meaning of a stimulus (e.g., semantic verification). For brevity, we refer to these as elementary and higher-order tasks, respectively. Our tasks can be further broken down into elementary paradigms using letter stimuli and otherwise identical paradigms using word stimuli. Thus, we have three groups of tasks to relate to reading: elementary-letter tasks, elementary-word tasks, and bigher-order tasks. The particular tasks used are given in Table 1 .

Two methodological notes are in order before describing our study in detail. The 
TABLE 1

InFORMATION PROCESSING TASKS

\begin{tabular}{|c|c|}
\hline \multicolumn{2}{|r|}{ 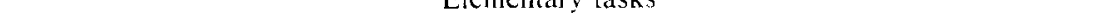 } \\
\hline Visual search & $\begin{array}{c}\text { Detect a target item among a set of } \\
\text { simultaneously displayed items. }\end{array}$ \\
\hline Matching & $\begin{array}{l}\text { Match a pair of items for physical } \\
\text { or name identity. }\end{array}$ \\
\hline Span of apprehension & $\begin{array}{l}\text { Report all of the items in a brietly } \\
\text { displayed array. }\end{array}$ \\
\hline \multicolumn{2}{|c|}{ Higher-order tasks } \\
\hline Lexical decision & $\begin{array}{l}\text { Determine whether an item is at } \\
\text { word or not. }\end{array}$ \\
\hline $\begin{array}{l}\text { Picture-sentence } \\
\text { vcrification }\end{array}$ & $\begin{array}{l}\text { Determine the correspondence between } \\
\text { a picture and a sentence. }\end{array}$ \\
\hline Semantic decision & $\begin{array}{l}\text { Determine the truth of a sentence } \\
\text { specifying categorical relations between } \\
\text { words. }\end{array}$ \\
\hline
\end{tabular}

first concerns the need to control for "apparatus" effects. To measure reading, one simply asks people to read passages, and then to answer questions about the material they have read. Measures of information processing ability are usually more exotic: certainly the computer-controlled displays and keyboards of the typical reaction time study are unfamiliar to most subjects. In fact, if parallel "paper and pencil" and computer-controlled display techniques are used to measure the same cognitive ability, then a factor associated with "ability to manipulate the apparatus" will emerge (Lansman, Donaldson, Hunt, \& Yantis. 1982). This type of individual difference could complicate our results. To avoid this problem, we had our subjects perform a choice reaction time task that required rapid manipulation of the response apparatus following a nonlinguistic display. Performance in this task then could be used as a covariate in analyzing the relation between information processing and reading measures. In addition, we measured a variety of psychometric tasks as possible controls for other specific abilities. These included intelligence and memory span measures.

The second methodological note concerns our analysis. We used the Analysis of Covariance Structure method. For readers not familiar with this method, our application of it can be thought of as a factor anal$y$ sis with the factor structure fixed in advance. This structure is then used to predict the pattern of individual differences. The output of the analysis is the set of parameters that maximizes the fit of the specified model to the observed correlation matrix. Also produced is a $\chi^{2}$ evaluation of the model's goodness of fit. The method is described in detail by Jöreskog and Sörbom (1978), Jöreskog (1974), and by Bentler (1980). Frederiksen (1982) and Geiselman. Woodward, and Beatty (1982) illustrate its application to research on reading and information processing.

\section{METHOD}

\section{Subjects}

Subjects were selected on the basis of their reading comprehension scores on the Washington pre-college test (1977). This test is a group-administered scholastic aptitude test given to Washington State high school students who plan to attend college. On the reading comprehension subtest, students are given a fixed amount of time to read passages and answer questions about them. Reading comprehension is scored by the number of questions answered correctly. The range of reading comprehension 
scores of University of Washington students was divided into six intervals. Students were invited to participate until we obtained 15 subjects in each interval. Of a total 91 subjects, 46 were males and 45 were females balanced as well as possible over the six groups. Subjects were sophomores and juniors currently enrolled at the University of Washington, were native speakers of English, and had no uncorrected visual or auditory defects. They were paid $\$ 3.00$ per hour plus a $\$ 5.00$ bonus for completing the study. Seventy-five of the subjects returned for a follow-up session that occurred 5 months after the original study.

\section{Overall Procedure}

The study was conducted in seven sessions with small groups of subjects $(\leqslant 10)$. For the first four sessions, subjects spent 50 minutes each day performing the reac- tion time tasks. In the fifth session, subjects performed the choice reaction time task. the span tasks, and a reading speed test. The sixth session was 90 minutes long, and consisted of the Nelson-Denny reading and Raven intelligence tests. The final session lasted 2 hours and consisted of the modified-Davis listening and reading comprehension tests and the experimental reading speed tests. A fixed schedule of tasks, shown in Table 2, was followed because counterbalancing was not feasible.

\section{Apparatus}

A Nova 820 computer controlled stimulus presentation and response collection for the reaction time tasks. Subjects were seated in individual sound-attenuating booths. Each booth contained a keyboard for responses and an independently controlled Tektronix 604 cathode-ray tube oscilloscope for stimulus presentation. The

TABLE ?

THE SCHEdLIf. OF TASKS

\begin{tabular}{|c|c|c|c|c|}
\hline Session & First lask & Second lask & Third task & Fourth lask \\
\hline 1 & $\begin{array}{l}\text { Two-cloice } \\
\text { reaction time }\end{array}$ & $\begin{array}{l}\text { Matching } \\
\text { with letters }\end{array}$ & $\begin{array}{l}\text { Visual search } \\
\text { with letters }\end{array}$ & \\
\hline 2 & $\begin{array}{l}\text { Two-choice } \\
\text { reaction time }\end{array}$ & $\begin{array}{l}\text { Matching } \\
\text { with words }\end{array}$ & $\begin{array}{l}\text { Visual search } \\
\text { with words }\end{array}$ & \\
\hline 3 & $\begin{array}{l}\text { Two-choice } \\
\text { reaction time }\end{array}$ & $\begin{array}{l}\text { I.exical } \\
\text { decision }\end{array}$ & $\begin{array}{c}\text { Picture-sentence } \\
\text { Verification }\end{array}$ & \\
\hline 4 & $\begin{array}{l}\text { Two-choice } \\
\text { reaction time }\end{array}$ & $\begin{array}{l}\text { Semantic } \\
\text { decision }\end{array}$ & Inference ${ }^{t t}$ & \\
\hline 5 & $\begin{array}{l}\text { Two-choice } \\
\text { reaction time }\end{array}$ & $\begin{array}{l}\text { Span of } \\
\text { apprehension } \\
\text { with letters } \\
\text { and words }\end{array}$ & $\begin{array}{l}\text { Memory span } \\
\text { with letters } \\
\text { and words }\end{array}$ & $\begin{array}{l}\text { Minnesota speed } \\
\text { of reading test }\end{array}$ \\
\hline 6 & $\begin{array}{l}\text { Nelson-Denny } \\
\text { reading rate and } \\
\text { comprehension }\end{array}$ & Raven matrices & & \\
\hline 7 & $\begin{array}{l}\text { Modified-Davis } \\
\text { comprehension } \\
\text { tests: } \\
\text { Listening } \\
\text { Reading } \\
\text { Listening } \\
\text { Reading }\end{array}$ & $\begin{array}{l}\text { Experimental } \\
\text { reading } \\
\text { speed } \\
\text { test }\end{array}$ & & \\
\hline
\end{tabular}

"Inference" was a reaction time inference task loosely based on Anderson and Bower's (1973) work. Unfortunately, the main effects were not anticipated and hence it is not included in the individual differences anilyses 
span tasks used the same apparatus as the reaction time tasks except that the subject wrote (rather than keyed) the response. The listening comprehension task used a TEAC Model 1230 tape recorder. a Heathkit Model AA-18 amplifier, and a Realistic Solo-4 speaker.

\section{Psychometric Measures}

The psychometric tests were group administered in a large room. The tests were timed, and subjects were told to work as quickly as possible without making errors. Each test consisted of a test booklet and a separate answer sheet.

1. Nelson-Denny reading test. Form A of the comprehension and reading speed portion of the Nelson-Denny (1960) test was administered. Subjects were given 20 minutes to read eight selections and answer four multiple-choice questions at the end of each selection. While answering questions. subjects were allowed to refer back to a passage. If they had difficulty with a question, they were told to make a reasonable effort and then go on to the next question.

The first minute of the test was used to determine reading speed. Subjects began reading the first passage and, at the end of 1 minute. were told to stop on the line they were reading and record that line on their answer forms. They then returned to their reading.

2. Other reading speed tests. There were two additional tests of reading speed. The experimental reading speed test consisted of 10 passages that were taken from a variety of magazines and textbooks. Each passage was between 300 and 500 words in length and was followed by a page containing three multiple-choice questions. Subjects were instructed to read each passage in their normal way. At the end of 45 seconds, they were told to stop and record the line number that they had reached. Subjects were advised that it was in their best interest to mark line numbers accurately. because scores on the questions would be calculated only from material that had been read. If they claimed to have read eitner more or less than they actually had, they would lower their scores. After marking the line number for a passage. subjects turned the page and answered the comprehension questions. They were given 1 minute before they were instructed to turn the page and read the next passage.

Also administered was the Minnesota speed of reading test (Eurich, 1964). It consists of 36 short paragraphs, cach containing an irrelevant phrase. The task is to cross out as many such phrases as possible in 5 minutes.

All three reading speed measures, the Nelson-Denny, our experimental measure. and the Minnesota, are usually expressed in terms of material read within a unit of time. Here, this scale was transformed into the inverse measure, the time to read a unit of material (i.e., milliseconds per word). This latter measure corresponds more closely to the reaction time measures and can be interpreted in terms of the duration of mental processing.

3. Modified-Dayis reading and listening comprehension. The reading and listening comprehension tasks were based on identical materials. Forms A through D of the Davis reading test (Davis \& Davis, 1962) were used, with the original forms modified by deletion of passages and questions that contained references to tables or specific line numbers. Each modified form contained 12 passages and 45 questions. Forms $A$ and $D$ were made into separate booklets for the reading comprehension task. Forms $B$ and $C$ were tape-recorded for the listening task. The listening tapes were alternated with the reading booklets.

For the reading task, subjects were instructed to read each passage carefully and then answer the questions without referring back to the material. Each passage in a booklet was followed by a page containing several multiple-choice questions. Subjects were told to guess only if they could rule out one or more of the five alternatives. Twenty minutes were allotted for each of the two booklets.

During the listening task, subjects lis- 
tened to a tape-recorded passage and then answered questions. The passages and questions were recorded in a normal speaking voice, at an average speed of 200 words per minute. Thirty minutes were allotted for each of two tape recordings.

4. Raven progressive matrices. This standardized nonverbal intelligence test contains 36 items (Raven, 1965). Each item is a $3 \times 3$ matrix with a missing entry in the lower right corner. The task is to choose the missing element from among eight alternatives by determining the rule used to construct elements across rows and down columns. Subjects were told to be sure they had the correct answer before continuing to the next problem. They were given $5 \mathrm{~min}$ utes to complete 10 practice problems, and 40 minutes to complete the 36 test problems.

5. Washington pre-college test. In addition to the reading comprehension measure, we used six measures from this test.

(a) The Vocabulary subtest has students select the correct synonym for a given word.

(b) The English-usage subtest measures the ability to use grammar, punctuation, word choice, and capitalization rules.

(c) The Spelling subtest measures the ability to select a misspelled word from a set of words.

(d) The Quantitative subtest included three scores: Mathematics achievement, Quantitative skills, and Applied mathematics.

(e) The Mechanical-reasoning subtest measures the ability to answer questions about illustrations of mechanical systems.

(f) The Spatial-ability subtest requires students to visualize how a two-dimensional figure would look in three dimensions if folded on certain lines.

\section{Information Processing Tasks}

Reaction time tasks. For all of the reaction time tasks, subjects were instructed to work as quickly as possible without making errors. Accuracy was stressed more than speed, and subjects were told their data could not be used if they made more than 10 errors per task (about $8 \%$ errors).

The following general procedures were followed. After each trial on a given task. subjects received visual feedback ("OK" or "NO") for 500 milliseconds. After every eight trials, subjects saw their mean reaction times from these eight trials and their accumulated total number of errors. When they were ready to begin the next set of eight trials, they pressed a key and the next trial began in 250 milliseconds. Thereafter. trials were spaced 500 milliseconds after trial feedback. Every trial was preceded by a warning dot which appeared for 250 milliseconds followed by a 250 -millisecond interval before the stimulus onset.

For all reaction time tasks, there were two possible responses. Depending on the task, subjects used the right key on their response boards for a "same," "yes," or "right" response, and the left key for a "different," "no," or "left" response. Stimuli always remained on the screen until the subject responded. Stimuli for each task were presented in a randomly permuted order. This order was the same for all subjects, consistent with our decision to make procedures identical for all subjects. In addition, subjects were given one or two sets of practice trials before each experiment and were encouraged to ask questions if they did not understand.

1. Two-choice reaction time. In the twochoice task, three stars were displayed to either the left or the right of fixation. Subjects were instructed to press the right key with their right index finger if the stars were on the right, and to press the left key with their left index finger if the stars were on the left. There were eight practice trials and 48 test trials. This was the first task performed in each of the five sessions because it refamiliarized subjects with the apparatus and provided a control measure of the ability of subjects to perform the basic elements of all reaction time tasks. 
2. Visual search. The search task required the subject to detect a target among a set of visually presented items (Sternberg \& Scarborough, 1969). On each trial, a single target item, either a letter or a word. was presented for 250 milliseconds. It was then replaced by a search set of from two to five similar items. If the target item appeared in the search set. subjects responded yes by pressing the right key, otherwise they responded no by pressing the left key. There were 32 practice and 128 test trials. The four set sizes occurred equally often and were presented in random order. On half of the trials, the target item appeared in the search set; serial position was counterbalanced on these trials.

In the letter version of the task, items were constructed from 24 lowercase letters. On each trial, letter strings were sampled without replacement. In the word version of the task, the items were selected from a set of 24 common four-letter words (see Appendix A). All words were presented in lowercase.

3. Matching. The matching task required subjects to determine whether two items had the same name (Posner \& Mitchell, 1967). The stimulus set for letter marching was constructed from the 16 letters listed in Appendix A. These letters appeared in randomly chosen pairs, using all permutations of uppercase and lowercase letters. Subjects were to respond same by pressing the right key if the letters had the same name, regardless of whether or not they also had the same case. Otherwise, subjects were to respond different by pressing the left key. Of the 128 test pairs. 32 were physically identical, 32 were name identical but physically dissimilar (different case), and 64 were pairs of letters with different names.

In the word version of this task, the stimuli were 32 pairs of common four-letter words (see Appendix A). The different trials consisted of word pairs differing by one letter (e.g., SINK, WINK), with the changed letter balanced over position. The words were presented in upper- or lowercase, side by side, with one character space between words.

4. Lexical decision. The lexical-decision task required subjects to judge whether an item was a word (Rubenstein, Lewis, \& Rubenstein. 1971). The stimulus set (ct. Appendix A) was made up of the lowercase word and nonword items used by Meyer. Schvaneveldt, and Ruddy (1972). Trials consisted of two items presented consecutively, with each item requiring a response. Subjects were instructed to press the right key if an item was a word, and the left key if it was not a word. If subjects missed one or both items on a trial, the entire trial was counted wrong. There were 16 practice trials and 128 test trials. These 128 trials consisted of 16 pairs of associated words. 16 pairs of nonassociated words, 32 words followed by nonwords. 32 nonwords followed by words, and 32 pairs of nonwords. The sequencing of the trial types was random.

5. Picture-sentence verification. This task required subjects to determine whether a sentence accurately described a picture (Clark \& Chase, 1972). The stimuli consisted of two pictures, lowercase descriptive sentences which varied in linguistic complexity (c.g., plus is above star; star is not below plus). Subjects saw one of the two possible pictures for 1500 milliseconds, followed by one of the sentences. If the sentence correctly described the picture, the subjects were instructed to press the right key; otherwise. they were to press the left key. There were 16 practice trials and 128 test trials. There were four equally frequent levels of sentence-picture complexity: true affirmative, false affirmative, true negative, and false negative. These four conditions can be further divided in terms of whether the top item in a picture matches or mismatches the first noun in a phrase. For example, a match case would be ${ }_{*}^{+}$followed by the sentence "plus is not above star." and a mismatch case would be : followed by the 
phrase "star is not below plus." Match and mismatch cases occurred equally often across the four trial types.

6. Semantic decision. The semantic decision task required subjects to determine whether a sentence was true based on their preexisting semantic knowledge. The stimuli were patterned after the set relations used by Collins and Quillian (1969). and appear in Appendix A. Specifically, 40 three-level semantic hierarchies were used to construct true and false sentences. Examples of the stimuli for this task are $A$ COBRA IS A COBRA (level zero). A COP. PERHEAD IS A SNAKE (level one), A PYTHON IS A REPTILE (level two), and A VIPER IS A VOLCANO (false). The sentences were presented in random order, one at a time, in uppercase letters. Subjects were instructed to press the right key if a sentence was correct, the left key if a sentence was not correct. There were 16 practice trials followed by 120 test trials. Half of the sentences were true and half were false, with each set containing 20 sentences at each lovel.

\section{Span Tasks: General Procedure}

In the span tasks, the stimuli appcared either simultaneously (Span of Apprehension) or successively (Memory Span). For each. subjects were told to watch closely and, at the end of a trial, to write the stimuli onto a response sheet in the order they were presented. Items recorded in the wrong order were counted incorrect and subjects knew that no item would be repeated on a single trial. An ascending "method of limits" design was used tef. Lyon, 1977) where the number of items per trial was increased by one after every three trials. The responses were scored with Brener's method of estimating the largest span that can be perfectly reported (see Lyon. 1977). As an illustration. if a subject worked up from four items per trial to six items per trial. and if three of the four-item trials were correct, two of the five-item trials were correct, and none of the six-item trials were correct, then the span score would be 4.66 .

Each span task began with three practice trials. When a subject was ready, they pressed a key and in $\mathbf{2 5 0}$ milliseconds a trial began. Each trial started with a fixation point in the same fashion as the reaction time tasks. The stimuli in each display consisted of a set drawn from either the letters or the words that were used in the search tasks. After the display, subjects could take as long as they wished to record the items. Feedback was given afterward, but only for the practice trials.

7. Memory span. In a trial, stimuli were presented one at a time at a rate of two per second. Four stimuli were presented for the three practice trials and for the first three test trials on both the letter and word versions of this task. With an itcm being added after every three test trials, eight items were presented by the end of the experiment. Subjects used separate response sheets for the letter and word versions of the task, but there was no difference between the sheets. Subjects were not permitted to write on the response sheets until a trial was completed.

8. Span of apprehension. Stimuli were presented simultaneously for 100 milliseconds. Because of the task's difficulty, two letters were presented for the three practice trials and first three test trials. With a letter being added after every three test trials, six letters were presented by the end of the 15 test trials. With word stimuli, a session began with single-word presentations and ended with five-word presentations.

\section{Results for Individual Tasks}

We first review the outcomes of the individual information processing experiments. Our intention is twofold: to demonstrate a qualitative replication of the paradigm's results, and to establish quantitatively reliable measures for further analysis. Qualitative results are discussed in both nomothetic and individual-subject terms. Quantitative effects are discussed 


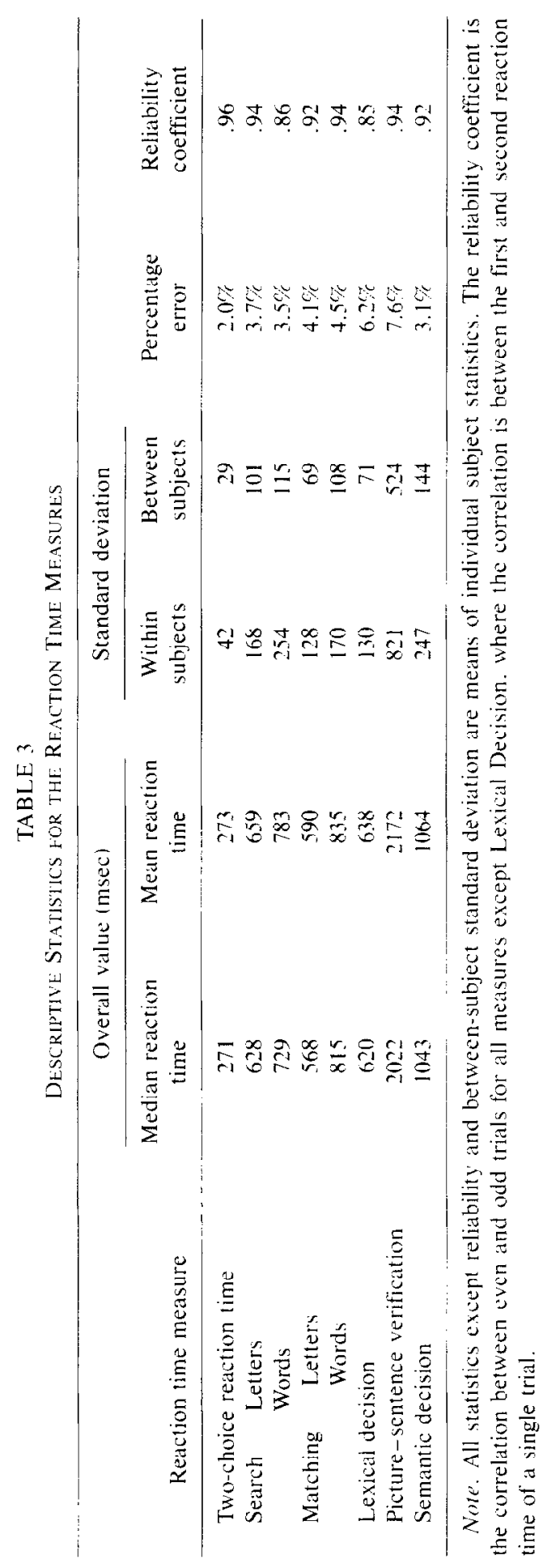

primarily in individual subject terms with reliabilities calculated across subjects. A collection of statistics concerning each measure is summarized in Tables 3 and 4 . including central tendency statistics, standard deviations both within and between subjects, and reliabilities. ${ }^{\prime}$ In general, all previously reported results were replicated.

1. Two-choice reaction time. Reaction time decreased steadily over sessions but there was also an increase in errors.

2. Visual search. Several alternative linear models have been used to describe search reaction time experiments, and our study replicates their general characteristics (cf. Sternberg, 1966: Theios. Smith. Haviland, Traupmann, \& Moy, 1973). As Figure 1 shows, the results fit a lineat model (letters, $r^{2}=.98$; words, $r^{2}=.97, n$ $=2$ ). A linear model was also fit for individual subjects (letters, mean $r^{2}=.84$ : words, mean $r^{2}=.95, n=21.2$

3. Matching. The matching experiment replicated the reaction time difference between name identity and physical identity matches (letters, $78 \pm 12$ milliseconds: words, $100 \pm 17$ milliseconds). This difference measure was calculated for each subject but did not prove reliable. Although previous work in our laboratory and elsewhere has shown this measure to be a reliable variable for individual differences research (Hunt, 1978). the number of trials used here was considerably less than the number used elsewhere. This would, of course, lower the reliability.

4. Lexical decision. The slower decision

I Typically, this involves calculation of split-half reliabilities over odd and even trials, although a few special cases are pointed ont. Reliabilities are not corrected for test length and, for this reason. may be seen as conservative estimates.

'Large serial position effects were found, with the distance from fixation accounting for as much overall variance as the set size (letters, $r=.84$ for set size. .39 for serial position; words, $r^{2}=.49$ for set size, .77 for serial position, $n=12$ ). It is worth pointing out that set size and serial position are not independent $(r$ $=.42 . n=12$ ). 


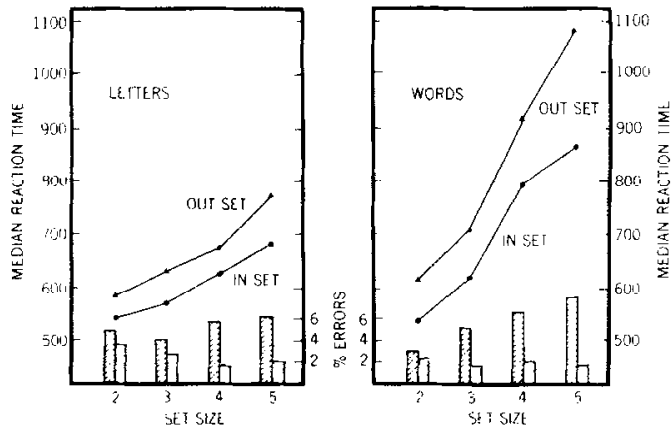

Fili. 1. Means of median reaction times and percentage of arrors for the visual search task as a function of search set size. The curve parameter represents whether the target was or was not in the presented search set. Darkened bars represent inset errors: open bars represent oul-of-set errors. The data are presented separately for letters and words.

times for nonwords as opposed to words was reliable for individual subjects (difference of $78 \pm 10$ milliseconds, reliability of $r=.65$ ). Although the semantic facilitation effect (Meyer et al., 1972) was also replicated ( $47 \pm 12$ milliseconds), it did not prove to reliable over subjects $(r<.3)$.

5. Picture-sentence verification. As Figure 2 illustrates, the original Clark and Chase (1972) experiment was replicated. A regression analysis shows that our data provide a good fit to their model $\left(r^{2}=.995, n\right.$

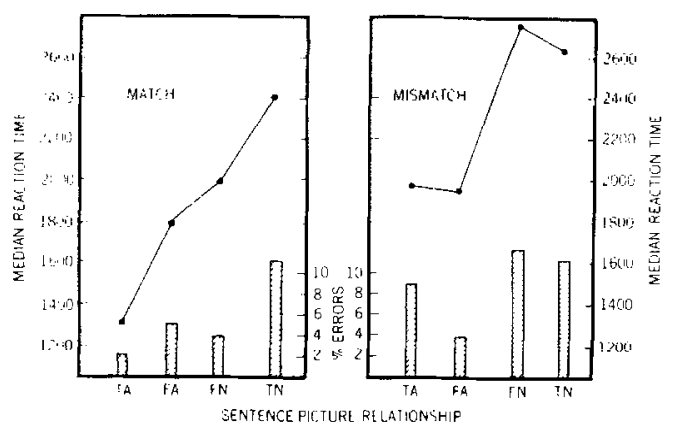

FIG. 2. Means of median reaction times and percentage of errors for the picture-sentence verification task as a function of picture-sentence relationship. The abscissa abbreviations stand for true affirmative (TA), false affirmative (FA), false negative (FN), and true negative (TN). Data are displayed separately for trials where the first term in the sentence is identical to the top element in the picture $(\mathrm{MATCH})$. and for trials where the first term in the sentence is identical to the bottom element in the picture (MISMATCH).

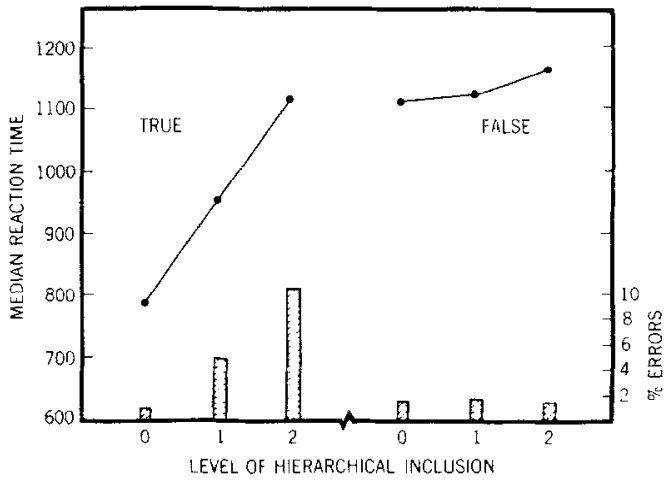

FiG. 3. Means of median reaction times and percentage of errors for the semantic decision task as a function of level of hierarchical inclusion. The data are shown separately for true and false trials.

$=3)$. The reliabilities of the individual parameters of the Clark and Chase model over 91 subjects were Subject matching, .64; Markedness, .24: Negation. .74: and Falsification, .40.

6. Semantic decision. The effect of hierarchical relationships reported by Collins and Quillian (1969) was replicated. The superordinate effect is illustrated in Figure 3. Unfortunately, while the critical difference between levels 1 and 2 is significant for the group data (225 \pm 36 milliseconds), the individual subject differences were not reliable $(r<.3)$.

7. Span of apprehension. The previously found differences in the tachistoscopic report of letters and words (Cattell, 1885) were replicated. In the letter version, subjects reported $3.9 \pm 0.1$ letters, while in the word version, subjects reported $8.8 \pm .4$ letters (the equivalent of 2.2 words).

8. Memory span. Little difference was observed between the number of letters reported $(5.2 \pm 0.2)$ and the number of words reported $(5.1 \pm 0.2)$. This was contrary to our expectation of an advantage for letters (cf. Cavanagh, 1972).

9. Psychometric measures. The psychometric measures are described in Table 4 in similar detail to the other measures.

10. Reading measures. Both of the locally developed reading measures proved to be reliable and correlated with the stan- 
TABLE 4

Descriptivf Statistic for thf Span and Psychometric Measures

\begin{tabular}{|c|c|c|c|c|}
\hline Measure & Mean & $\begin{array}{l}\text { Standard deviation } \\
\text { between subjects }\end{array}$ & $\begin{array}{l}\text { Number } \\
\text { of items }\end{array}$ & Reliability \\
\hline \multicolumn{5}{|l|}{ Memory spán } \\
\hline Letters & 5.26 & 0.80 & 15 & $2.6^{*}$ \\
\hline Words & 5.14 & 0.87 & 15 & $>6^{*}$ \\
\hline \multicolumn{5}{|c|}{ Span of apprehension } \\
\hline Letters & 3.86 & 1.6 & 15 & $>.6^{*}$ \\
\hline
\end{tabular}

of the reading, listening, and the information processing measures. These composites were formed by adding the standardized scores (mean 0, standard deviation 1) of selected measures. Specifically, the reading composites were formed by adding scores from each of the reading tests, and the information processing composites were formed by adding the scores from each task using similar materials (see Table 1). For example, the reading comprehension composite was formed from the Nelson-Denny, Washington pre-college, and both versions of the modified-Davis reading comprehension tests; the letter composite was formed from the letter search. letter match, and span-of-apprehension tasks.

The composites summarize the data and highlight three observations. First, the reading and listening comprehension measures are more closely related than are the reading speed and comprehension measures ( $r=.82$ versus .59). This observation is supported by the individual correlations between the individual measures. The individual correlations between reading comprehension and listening comprehension were $r=.74, .80, .68$, and between reading comprehension and reading speed were $r=$ .25 to .60 (see Table 12). Second, the letter measures show little relationship to reading $(r-.03, .03)$ while the word measures are related to reading, particularly reading speed $(r=.37, .23)$. Supporting this point. the individual correlations between any of the letter tasks and reading show no significant relationships (see Table 13). In contrast, the correlations between word tasks and reading speed range from $r=.09$ up to

\section{Listening and Reading Abilities}

Should a distinction be made between listening and reading or between speed and comprehension? One view is that there are distinct, interrelated abilities of reading and listening but no distinction between the abilities of reading speed and reading comprehension. This view was taken by Jackson and McClelland (1979), who combined different reading measures and used listening to "partial out" what is common between reading and listening abilities. The alternative view is to consider speed and comprehension tasks as requiring distinct abilities and to emphasize similarities between reading and listening. According to this view, reading speed and comprehension reflect largely separate abilities, each a distinct part of overall reading performance (e.g., Blommers \& Lindquisı. 1944: McConkie, et al., 1973). Reading and listening comprehension, furthermore, reflect a single, general comprehension ability rather than distinct abilities (e.g. Sticht. 1972).

These two positions can each be realized as a particular trait model of the relevant abilities. To provide relative evaluation of each position, the method of hierarchical model testing will be used. Specific models will be contrasted to a general model that subsumes each specific model as a special case. To illustrate, the two positions summarized above can be thought of as special cases of a three-factor model that postulates distinct, interrelated factors for reading speed, reading comprehension. and listening comprehension. The question becomes, does the general model provide a 
togram of our subjects' Nelson-Denny test scores plotted in terms of the norms for college students (Nelson \& Denny, 1960). The distribution, while predictably noisy, shows no significant deviation from the expected rectangular distribution $\chi^{2}(9)=9.56, p>$ 1. In particular, our sample is not biased to high, middle, or low ability readers. Thus, it approximates a normal university student population.

In summary, these preliminary analyses establish the features necessary to enter these measures into an individual differences analysis. First, each measure is reliable over trials or parallel forms. Second, each replicates the main effects established by previous nomothetic literature.

\section{Individual Difference Results and Discussion}

The individual difference results will be considered in four sections. The first introduces the results with composite measures. This is followed by three separate analyses of the individual measures, each addressing a distinct question. These are

(a) the relationship between listening and reading.

(b) the relationship between reading and the elementary tasks.

(c) the relationship between reading and the higher-order tasks.

Each relationship will be addressed by using structural equation models to test specific hypotheses.

\section{Overview of Correlational Results}

We first present some of the simple correlations between measures. To reduce the confusion that can occur in trying to interpret the sign of a correlation with many types of dependent variables, positive coefficients are reported for positive relationships throughout the paper. For example, since lower reaction times are associated with higher ability, the correlation between reaction time and reading ability is algebraically negative. Here a positive correlation is reported, since good performance in reaction time is found with good performance in reading.

There are 28 measures that were considered in the individual differences analysis. Twelve were from the information processing tasks including eight latency measures (median reaction times of correct trials), and four span measures (frequencies of correct report). Sixteen other measures were from psychometric tests including three reading speed measures (reading times for a word), four comprehension measures, and nine general ability measures (frequencies of correct response). A complete correlation matrix of these measures is given in Tables 11,12 . and 13 of Appendix $B$.

To summarize the results, Table 5 contains the correlations between composites

TABLES

CORRELATIONS AMONG SUMMARY VARIABIISS

\begin{tabular}{|c|c|c|c|c|c|c|c|}
\hline & 1 & 2 & 3 & 4 & 5 & 6 & 7 \\
\hline 1. Two-choice reaction time & .96 & & & & & & \\
\hline 2. Composite of reading speed testy & .21 & $9^{*}$ & & & & & \\
\hline 3. Composite of reading comprehension tests & .17 & .59 & $.7 *$ & & & & \\
\hline 4. Modified-Davis listening comprehension & .12 & .49 & .82 & .75 & & & \\
\hline 5 Composite of elementary letler tasks & .70 & .03 & .03 & .02 & $9^{*}$ & & \\
\hline 6. Composite of elementary word tasks & 58 & .37 & .23 & .18 & .69 & $.9 *$ & \\
\hline 7. Composite of higher order tasks & .65 & .46 & .45 & .30 & .60 & .71 & .96 \\
\hline
\end{tabular}

Vete. These correlations are based on a sample of 67 subjects. Reliabilities are given on the diagonal of this matrix

The reliability of this composite is only estimated dise to including measures without parallel scores. 
of the reading, listening, and the information processing measures. These composites were formed by adding the standardized scores (mean 0 , standard deviation 1) of selected measures. Spccifically, the reading composites were formed by adding scores from each of the reading tests, and the information processing composites were formed by adding the scores from each task using similar materials (see Table 1). For example, the reading comprehension composite was formed from the Nelson-Denny, Washington pre-college, and both versions of the modified-Davis reading comprehension tests: the letter composite was formed from the letter search, letter match, and span-of-apprehension tasks.

The composites summarize the data and highlight three observations. First, the reading and listening comprehension measures are more closely related than are the reading speed and comprehension measures ( $r=.82$ versus .59$)$. This observation is supported by the individual correlations between the individual measures. The individual correlations between reading comprehension and listening comprehension were $r=.74, .80, .68$, and between reading comprehension and reading speed were $r=$ .25 to .60 (see Table 12). Second, the letter measures show little relationship to reading $(r=.03, .03)$ while the word measures are related to reading, particularly reading speed $(r=.37, .23)$. Supporting this point. the individual correlations between any of the letter tasks and reading show no significant relationships (see Table 13). In contrast. the correlations between word tasks and reading speed range from $r=.09$ up to .47 , and between word tasks and reading comprehension range from $r=.00$ to .31 . Third, the higher-order measures are related to both reading speed and comprehension. Here, the individual correlations between higher-order tasks and reading ranged between .24 and .47. To pursue each of these observations further, we consider next analytic models of each ohservation.

\section{Listening and Reading Abilities}

Should a distinction be made between listening and reading or between speed and comprehension? One view is that there are distinct, interrelated abilities of reading and listening but no distinction between the abilities of reading speed and reading comprehension. This view was taken by Jackson and McClelland (1979). who combined different reading measures and used listening to "partial out" what is common between reading and listening abilities. The alternative view is to consider speed and comprehension tasks as requiring distinct abilities and to emphasize similarities between reading and listening. According 10 this view, reading speed and comprehension reflect largely separate abilities, each a distinct part of overall reading performance (e.g., Blommers \& Lindquist, 1944; McConkie, et al., 1973). Reading and listening comprehension, furthermore, reflect a single, general comprehension ability rather than distinct abilities (e.g., Sticht. 1972).

These two positions can each be realized as a particular trait model of the relevant abilities. To provide relative evaluation of each position, the method of hierarchical model testing will be used. Specific models will be contrasted to a general model that subsumes each specific model as a special case. To illustrate, the two positions summarized above can be thought of as special cases of a three-factor model that postulates distinct. interrelated factors for reading speed, reading comprehension, and listening comprehension. The question becomes, does the general model provide a reliably better fit to the data than a specitic model that assumes separate reading and listening traits, but makes no distinction between reading speed and reading comprehension?

The general model. The general model is shown in Figure 5. Following the conventions of covariance structure models, the figure shows observed measures as boxes. 


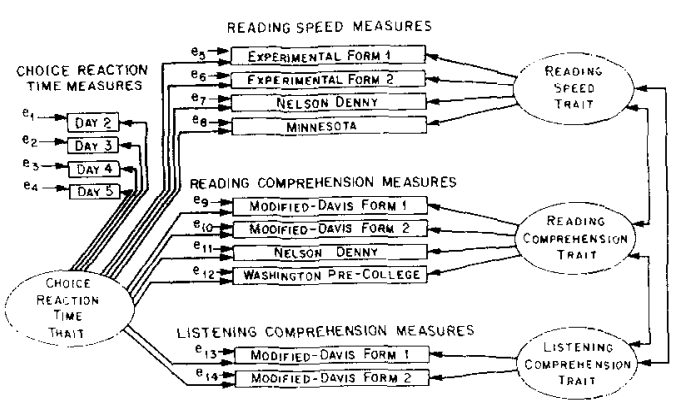

FIG. 5. A diagram showing the proposed relations between observed measures and proposed factors for the listening-reading general model. See text for explanation.

latent factors as circles, and the interrelationships with arrows. The absence of an arrow indicates no relationship. As illustrated, the three-factor model parallels the experimental design of reading speed. reading comprehension, and listening comprehension measures. In addition, a factor representing ability in choice reaction time is included to control for method-of-measurement ability differences. This factor becomes important in analyzing later models that introduce other reaction time tasks: here, it has little effect. ${ }^{3}$

The general model specifies trait factors for each of four sets of measurements. Each factor is directly associated with its own measures, but only indirectly associated with other measures via factor interrelationships. An exception is the choice reaction time factor which is defined to be directly associated with all tasks and defined to be unassociated with the other factors. The other factors, as a result, are required to be independent of the abilities associated with choice reaction time. In other words, the model "partials out" any ability uniquely associated with making speeded responses.

The general model in Table 6 does provide a reasonably good picture of the cor-

For the analysis of reading and listening, the inclusion of choice reaction time has little effect and models without it led to the same conclusions. The factor was included simply to maintain a similar model for all of the analyses. relational data. The upper part of the table contains the factor loadings that relate the observed measures to the inferred traits; the lower part of the table contains the interrelationships between the factors. Throughout the table, the italic 0 and $I$ values denote fixed parts of the model. All the other values are maximum likelihood estimates. There is a high relation between reading and listening comprehension, $\vec{r}=$ $.96 \pm .03$. This compares to $\hat{r}=.63 \pm .09$ between reading speed and reading comprehension and $\hat{r}=.55 \pm .10$ between reading speed and listening comprehension. These relations will be further examined in the analyses given below.

In spite of the fairly close agreement of the general model with the data. it cannot completely reproduce the correlation matrix. The deviation of the data from the model is statistically reliable $\left(\chi^{2}(64)=122\right.$. $p<.0001)$. This is largely due to imperfect parallelism between the converging measures for each trait. ${ }^{4}$

Testing the specific models. The specific models embody more severe restrictions of the trait factors. The restrictions are evaluated by considering the difference in the goodness of fit between the general model and the appropriate specific model. This

4 The fit of factor-analytic models is difficult to assess (Bentler \& Bonett, I980). An inspection of the residuals of our general model shows no noticeable pattern and only one residual greater than .16 the residual between Nelson-Denny reading comprehension and the Minnesota reading speed lests was .30). The remaining error is probably due to differences between the supposed parallel measures and not due to faults in the general factor structure. Nevertheless, a $x^{2}$ test of model fit shows a significant failure $\left(x^{2} 164\right)$ $=122 . p<.000 \mathrm{I}$. Obviously. the model can be improved: but, for our purposes might it be adequate? One proposed measure of model adequacy is the sta tistic $x^{2 / n}$. where $n$ is the degrees of freedom. This statistic has an advantage over a simple $x^{2}$ as a measure of degree of model fit since it is independent of the degrees of freedom. By this statistic. the general model fits better than most specific models tested later in the paper $\left(\chi^{2}: n=1.9\right.$ compared to values as high as 50). For these reasons, we argue that the general model is adequate as a basis for the analysis of specific questions about the factor structure. 


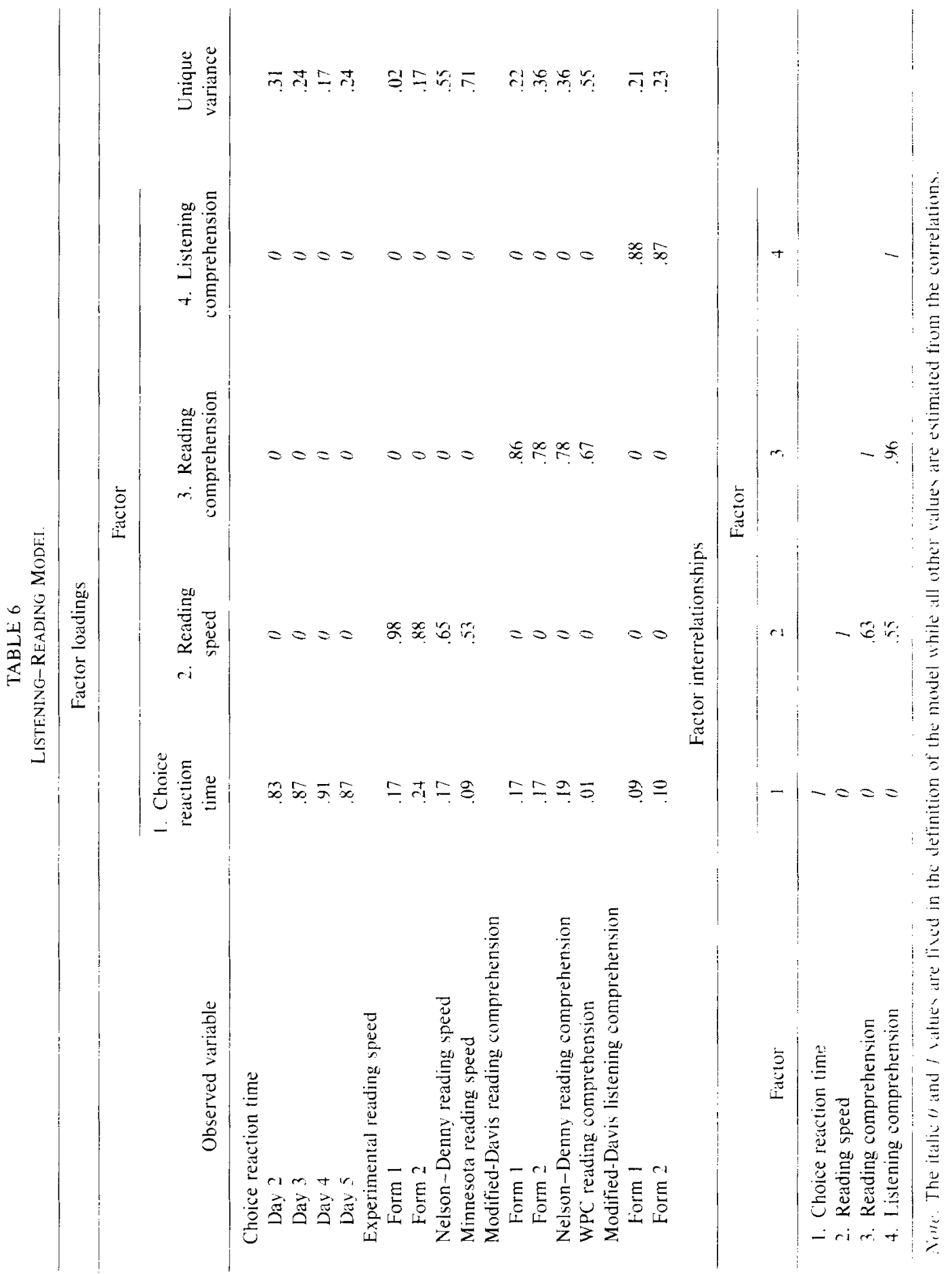


statistic follows the $\chi^{2}$ distribution, with the degrees of freedom equal to the difference between the degrees of freedom in the specific and the general model.

A "reading and listening" model was defined by combining the reading speed and comprehension factors into a single reading factor. There was a large decrease in the fit of the model, difference $\chi^{2}(2)=117, p<$ .001 . The reading and listening factors were highly related, $\hat{r}=.90 \pm .04$. The large $\chi^{2}$ indicates that it is not appropriate to combine reading speed and reading comprehension into a single trait.

A speed and comprehension model was then defined by combining the reading comprehension and listening comprehension factors into a general comprehension factor. There was an insignificant decrease in the fit, difference $\chi^{2}(2)=2.4, p>.1$. The relationship between speed and comprehension was substantial but not close to unity, $\hat{r}=.60 \pm .09$. Thus, the speed and comprehension restricted model does fit the data virtually as well as the general model.

\section{Reading and Elementary Information Processing Tasks}

The next analysis concerns the elementary tasks of search, matching, and span of apprehension. Recall that each task was performed with both letters and words. Three questions will be asked: were the letter and word tasks distinct, were they each related to reading, and were they equally related to speed and comprehension?

General model. Table 7 presents a general factor model for the tasks. Factors are defined to be related to only one or another of the classes of tasks: choice reaction time, reading speed, reading comprehension, letter tasks. and word tasks. Some tasks are related to two factors. For example. the letter-matching task is assumed to have been influenced by the letter factor and the choice reaction factor.

The main results are the trait interrela- tionships shown at the bottom of Table 7.5 The letter trait shows a near zero correlation with the reading traits. The word trait shows larger positive correlations to reading (with reading speed, $\hat{r}=.45 \pm .11$, and with reading comprehension, $\hat{r}=.20$ \pm .14). This pattern of correlations is very robust under a number of alternative models. For example, one can leave out the choice reaction time trait, leave out the span tasks. or build an explicit multimethod, multitrait model (Campbell \& Fiske, 1959) without changing the results.

Tests of specific models. Several restricted models were tested, using the $x^{2}$ difference technique described above. The results were as follows:

(a) Combining the letter and word factors led to a significant decrease in the fit of the model, difference $x^{2}(3)=22.4, p<$ .001 . Hence, separate factors are necessary for letter and word tasks.

(b) Constraining the relationship between the letter factors and reading factors to zero did not reduce the fit of the model, difference $\chi^{2}(2)=1.3, p>.1$.

(c) By contrast, constraining the relationship between the word factors and reading factors did lead to a significant decrease in model fit, difference $x^{2}(2)=12.5$. $p<.01$.

(d) Constraining the relationship between reading and letter factors to be the same as between reading and word factors did significantly decrease the fit of the model, difference $\chi^{2}(2)=18.2, p<.001$.

(e) Restricting the relationship between word and reading speed factors to be the same as the relationship between word and

\footnotetext{
Overall, the model is an acceptable fit. with a significant $x^{2}\left(\chi^{2}(115)=228\right)$ but one that is only about twice its degrees of frecdom. Furthermore. the residuals were again small. with only one exception. That exception is the residual between the two span-ofapprehension 1asks $(r-\hat{r})=49$. Fidently, performing span of apprehension involves an additional skill that is distinct from the other information processing tasks. The ability to perform in span of apprehension was also not related to memory span tsee Appendix BI.
} 


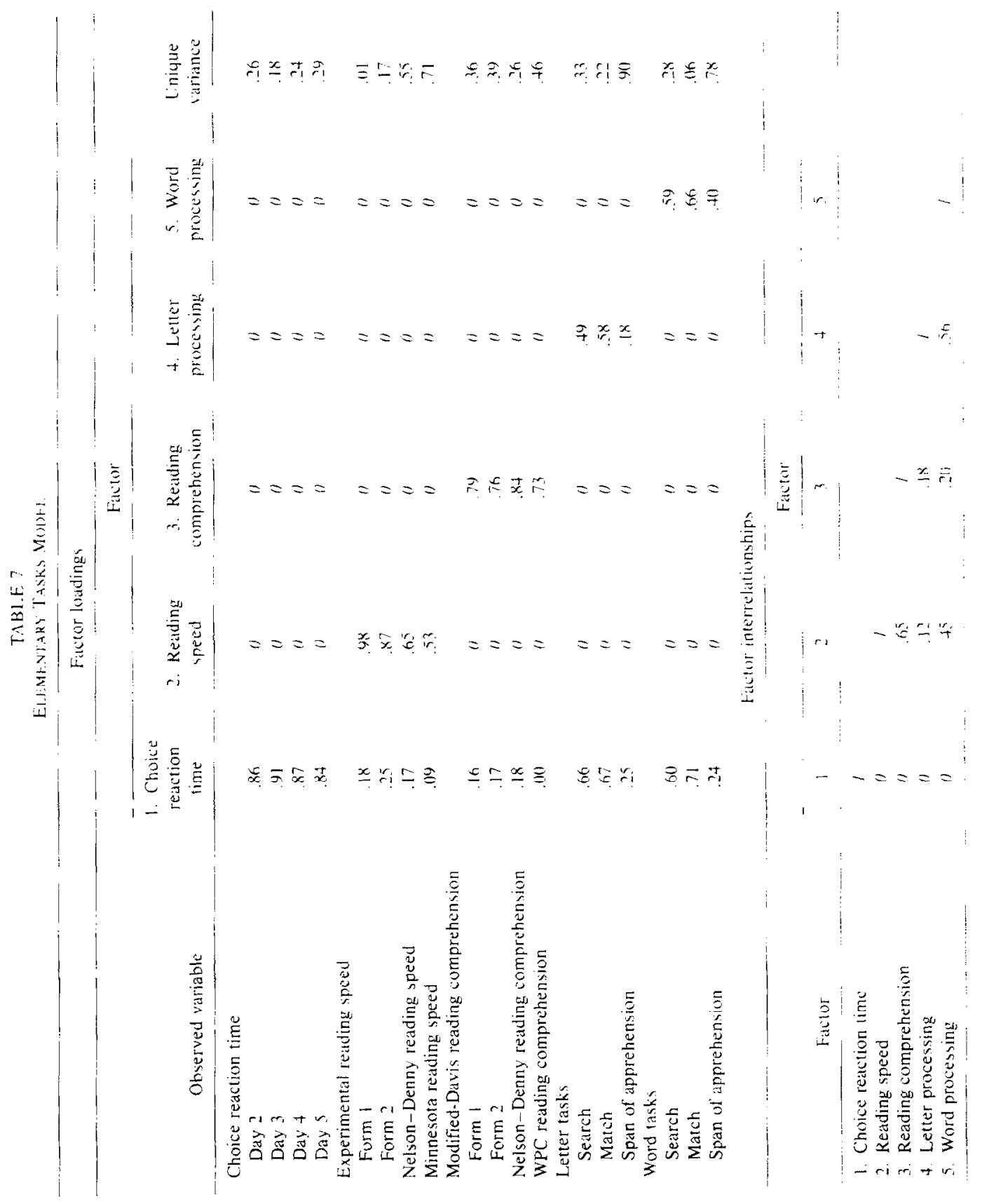


reading comprehension factors also reliably decreased the fit, difference $x^{2}(1)=5.5, p$ $<.05$ (combined $\hat{r}=.40$ ).

On the basis of these analyses. we can conclude two things, one confirming other results and one more novel. First, the letter and word tasks involve distinct abilities that have different relationships to reading ability. The letter tasks are not related to reading while the same tasks with words are related to reading. This conclusion goes beyond related work (e.g., Katz \& Wicklund, 1972: Jackson \& McClelland. 1975) by demonstrating the pattern in several tasks and by using a more general statistical model than in earlier studies. Second, the word tasks were more related to reading speed than reading comprehension. This difference was unexpected although. in retrospect, one might have anticipated it from work on paper and pencil tests (Holmes, 1954). The second result also supports our decision to consider speed and comprehension as separate abilities.

Alternative interpretations. The correlations between the reading measures and word tasks may have a number of sources. One "uninteresting" explanation is that the observed correlations could be due to systematic changes in accuracy criteria. For example, word matching might be positively correlated with reading comprehension because good readers guess the identity of words earlicr in speeded tasks. One would. then. expect good readers to show more errors in the reaction lime lasks. More generally, this speed-accuracy explanation implies that error measures and reaction time measures should have correlations of opposite sign with the reading measures ict. Jackson \& McClelland. 1979).

To evaluate this possibility, we had to look for a general effect over tasks, since errors in individual tasks were too infrequent to be reliable. A composite error measure was obtained for each individual by summing his or her standardized error scores from each of the reaction time tasks.
The composite error measure showed consistent negative correlations with the reaction time tasks $(r=-.25$ to -.45$)$. These reflect the usual speed-accuracy trade-off. However, the error measure was uncorrelated with all of the psychometric tasks, including the reading measures (e.g. . with modified-Davis reading comprehension $r=$ .05 , with experimental reading speed $r=$ $.00)$. Thus an accuracy bias could not have accounted for the correlations between the word tasks and reading.

\section{Reading and the Higher-Order \\ Information Processing Tasks}

The next analyses concern the higherorder tasks: lexical decision, picture-sentence verification, and semantic decision. Two questions will be asked. Do the higherorder tasks tap skills not tapped by the elementary tasks? If they do, are the higherorder skills related to reading? We also consider whether the lexical decision task is better grouped with the word or with the higher-order tasks. This question is of interest because lexical decision is the only higher-order task that involved single words rather than groups of words.

General model. The general model is presented in Table 8.6 It resembles the general model of Table 7, except that the word and higher-order tasks are considered, rather than word and letter tasks. Two results are of interest. The lexical decision measure was allowed to load on either the "word" or "higher-order" factor. It clearly was identified with the higher-order factor. The relevant loadings are $.07 \pm .12$ and $.49 \pm$ .12. In contrast to other analyses, this result was sensitive to the particulars of the model such as partialing out choice reaction time. ${ }^{7}$ Second, unlike the word factor. the

\footnotetext{
"The model fit is again acceptable, with a $x^{2}\left(y^{2}(114)\right.$ $=208$ ) that is less than twice its degrees of freedom and has no interpretable patterns in the residuals.

Some qualifications are required for the conclusion that lexical decision requires abilities more like the higher order tasks than the word tasks. First, it depends on accepting the model of partialing out choice
} 
higher-order factor was correlated both with the reading speed factor, $\vec{r}=.51 \pm$ .10 and with the reading comprehension factor, $\hat{r}=.55 \pm .10$. These correlation estimates were quite robust over variations in the model.

Tests of specific models. As before, we restricted this general model to test a number of specific hypotheses about the trait interrelationships.

(a) Constraining the lexical decision task to load only on the higher-order factor did not significantly decrease the model fit, difference $\chi^{2}(1)=.3, p>.1$.

(b) Constraining the lexical decision task to load only on the word factor did reliably decrease the model fit, difference $\chi^{2}(1)=$ 11.7. $p<.01$. The lexical decision task clearly is more like the higher-order tasks than like the word tasks. The remaining analyses are based on a general model with lexical decision only loading on the higherorder factor. ${ }^{8}$

(c) Combining the word and higher-order factors led to a reliable decrease in the fit of the model, difference $\chi^{2}(3)=35.0$, $p<.001$.

(d) Restricting the correlation between the reading and higher-order factors to zero reliably decreased the fit of the model, difference $\chi^{2}(2)=23.7, p<.001$.

(e) Restricting the relationship between reading speed and higher-order factors to be the same as the relationship between reading comprehension and higher-order factors did not reduce the model fit, differ-

reaction time abilities since otherwise all of these tashs demand similar abilities. Second, it depends on exactly which higher-order tasks you consider; in particular, lexical decision is much more closely related to the semantic decision task than to the picture-sentence verification task. Combining these tasks into ono factor is an approximation that is necessary due to the limited scope of our investigation of more complex information processing tasks. Nevertheless. the current analysis indicates that all three of these tasks show similar correlations with both reading comprehension and reading speed.

${ }^{8}$ Similar results are obtained with constraints on the original model. ence $x^{2}(1)=.13, p>.1$. The equated correlations to reading were $\hat{r}=.53 \pm .09$.

These analyses provide both confirmation of previous results and some new results. The higher-order tasks involve skills not tapped by either choice reaction time or elementary-word tasks. Furthermore. the lexical decision task is more like tasks involving sentences than tasks involving single words. With respect to reading, the reliable relationship between higher-order tasks and reading is not surprising: what is more interesting is that the higher-order and word traits show different relations to reading. The higher-order tasks are related to both reading comprehension and reading speed, while word tasks appear to be related to speed but not to comprehension. The difference in the pattern of correlations is further evidence for the need to define separate (though correlated) speed and comprehension traits.

\section{Summary of Results}

To summarize the results of this series of analyses, we constructed a final model that combines all three of the previous general models. The trait interrelationships of the combined model are shown in Table 9. The model is now entirely parallel to the composite measure analysis of Table 5 . The convergence of these analyses is reassuring. The new model was then restricted as shown in Table 10. Reading and listening comprehension factors were combined; the letter factor and reading factor were made independent: and the relations between the higher-order factor and the two reading factors were equated. These restrictions did not significantly reduce the model fit, difference $\chi^{2}(8)=10, p>.1$. The specialized model is further evidence for the following statements:

(a) listening comprehension trait and reading comprehension trait were the same in our sample,

(b) ability in letter tasks was not related to reading.

(c) speed and comprehension abilities 


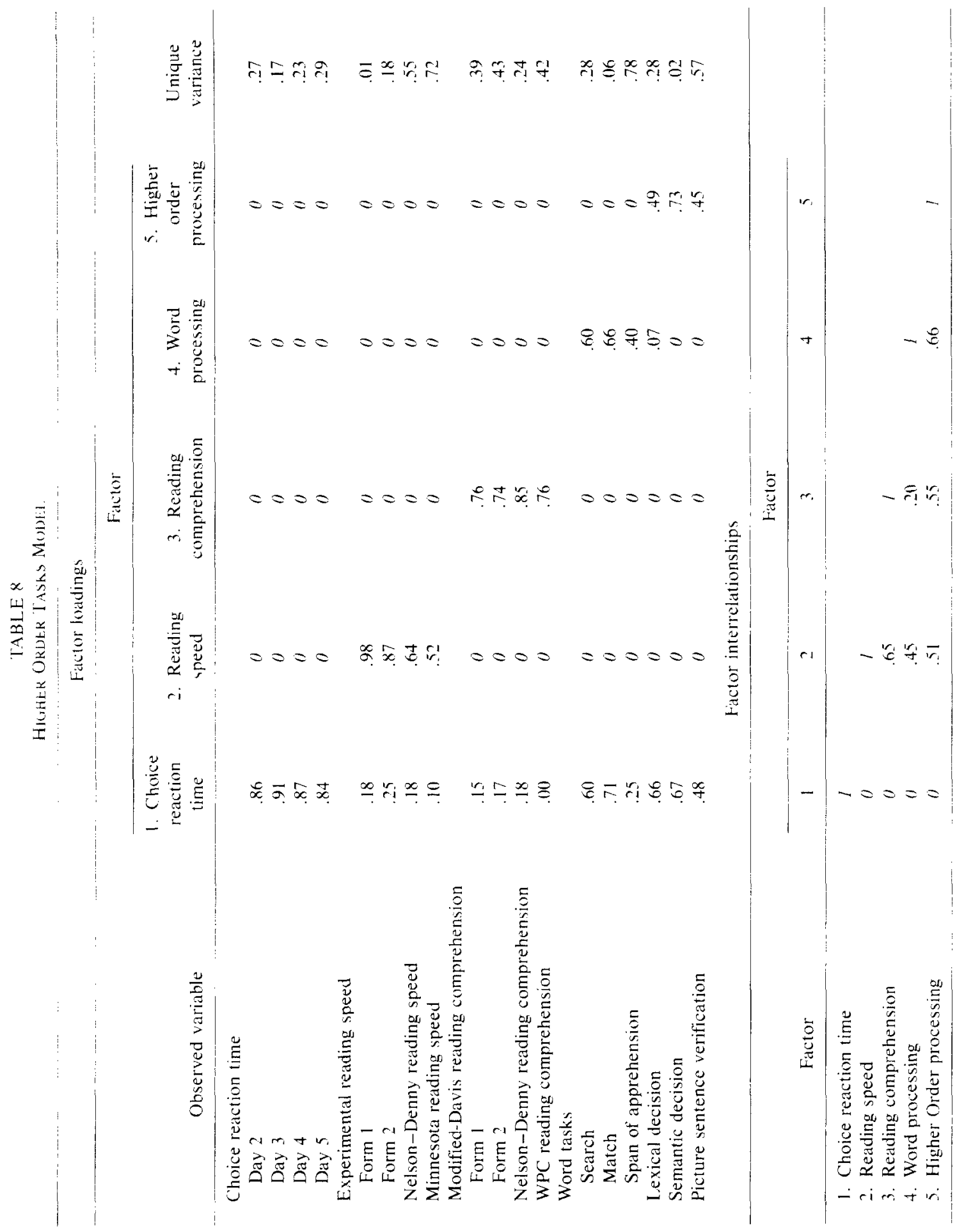


TABLE, Y

FaCtOr INTERRFi atIONShIPS for General Modhl of All. Variables

\begin{tabular}{|c|c|c|c|c|c|c|c|}
\hline \multirow[b]{2}{*}{ Factor } & \multicolumn{7}{|c|}{ Factor } \\
\hline & 1 & 2 & 3 & 4 & 5 & 6 & 7 \\
\hline 1. Two-choice reaction time & 1 & & & & & & \\
\hline 2. Reading speed & $\theta$ & 1 & & & & & \\
\hline 3. Reading comprchension & 0 & .64 & 1 & & & & \\
\hline 4. Listening comprehension & 0 & .56 & .96 & 1 & & & \\
\hline 5. Letter processing & 0 & -.14 & -.15 & -.13 & 1 & & \\
\hline 6. Word processing & 0 & .45 & .20 & .09 & .57 & $l$ & \\
\hline 7. Higher order processing & 0 & .52 & .53 & .35 & .28 & .69 & 1 \\
\hline
\end{tabular}

were equally related to higher-order tasks but differentially related to the ability to do word tasks, where speed shows the larger relationship.

\section{General Discussion}

Perhaps the most secure result of the study is a replication of the small to moderate correlations previously found between select information processing measures and reading (or other indices of verbal ability). Such a replication is important for several reasons. First it used a larger sample size and improved statistical analyses. More importantly, it also addressed the problem of removing method factors from the information processing measures. Additionally, we found moderate correlations between higher-order tasks and reading. What can be concluded from these results?

It is necessary to distinguish between reading as an elementary information processing act and as a language comprehension act. Measures of reading comprehension alone do not measure individual differences in the uniquely visual processing aspects of reading, because reading comprehension can be predicted almost perfectly by a listening measure. Indeed, one can substitute listening comprehension, which obviously does not depend upon visual processes, for reading comprehension without much alteration in the pattern of individual differences (cf. Sticht. 1972). The correspondence between reading and listening does not mean that the pattern of individual differences in comprehending written material is identical to the pattern of individual differences in comprehending normal speech, for we did not measure the latter. Normal speech uses a somewhat different grammer than written speech, and places more reliance on the pragmatics of

TABLE 10

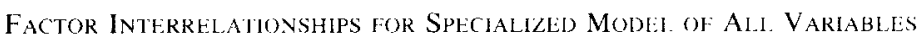

\begin{tabular}{|c|c|c|c|c|c|c|}
\hline \multirow[b]{2}{*}{ Factor } & \multicolumn{6}{|c|}{ Factor } \\
\hline & 1 & 2 & 3 & 4 & 5 & 6 \\
\hline 1. Two-choice reaction time & $l$ & & & & & \\
\hline 2. Reading speed & 0 & $l$ & & & & \\
\hline 3. Comprehension & 0 & .60 & 1 & & & \\
\hline 4. Letter processing & 0 & 0 & 0 & 1 & & \\
\hline 5. Word processing & $\theta$ & .49 & .23 & .62 & 1 & \\
\hline 6. Higher order processing & 0 & .51 & .51 & .34 & .69 & 1 \\
\hline
\end{tabular}


the situation than does writing. Our listening comprehension measure is more properly interpreted as a measure of the ability to comprehend written English, with the visual component of reading removed.

Given the similarity between comprehension measures, it is reasonable to expect that reading speed would be more closely related to the visual processes than would reading comprehension. This proved to be the case. Elementary information processing tasks, which required the identification of visual symbols but did not require manipulation of meaning, were related to reading speed but not reading comprehension. Hence. Jackson and McChelland's results are supported with respect to reading speed, but not with respect to reading comprehension. In fact, Jackson and McClelland (1979, p. 168) mention that their reaction time measures correlated more highly with differences in reading speed than with differences in comprehension.

The comparison to Jackson and $\mathrm{Mc}$ Clelland s study can be made more precise by considering the details of their multiple regression analysis. In that analysis, they predicted a composite reading measure with listening comprehension, letter de coding. and homonym accuracy. They claim to have accounted for nearly all of the variance in common between their reading measures. Specifically, using just their measures of listening comprehension and letter decoding, they could account for $80 \%$ of the variance in reading scores. Our trait interrelationship estimates can be used to determine how much variance could be accounted for in a similar model using our corresponding measures. To make this calculation, we used our reading speed trait in place of their composite reading measure and our word processing trait in place of letter decoding. The illustrative calculation uses the correlation estimates from Table 9: Listening Comprehension $\times$ Reading Speed, $r=.56$; Word Trait $\times$ Reading Speed, $r=.45$ : and Listening Comprehen- sion $\times$ Word Trait. $r=.09$. These produce a multiple $r$ of .69 between reading speed and the combination of listening and word processing traits. In other words, listening and word abilities can account for $47 \%$ of the variance in reading speed. By comparison, if we try to predict reading comprehension instead of reading speed, then the listening comprehension measure alone would account for nearly all of the reliable variance $(92 \%)$. Thus, by separating the two reading measures, one obtains very different pictures of the relevant predictor variables.

The relationship between the memory access hypothesis (cf. Jackson \& McClelland. 1979) and the observed distinction between letter and word tasks is somewhat problematic. There are two potential problems. The first problem is the absence of correlations with reading for any of our letter tasks. Previous studies have found such correlations for letter-matching tasks (Hunt, Frost. \& Lunneborg, 1973: Hunt, Lunneborg, \& Lewis, 1975: Lansman et al., 1982: Jackson $\&$ McClelland, 1979). The earlier studies relied on the contrast between trials in lettermatching tasks that required matching on name or physical identity, whereas we did not distinguish between the two types of trials. Statistical analyses of the carlier studies have indicated that the previously reported correlation is due to the contrast between trials, a measure not available in this study (see the earlier discussion of the letter-matching results; Donaldson. 1983: and Jackson, 1980).

The second problem is the presence of correlations between word tasks and reading and the absence of similar correlations between superficially identical letter tasks and reading. Such a difference is not predicted from the memory access hypothesis. To maintain this hypothesis, we propose that words result in an obligatory memory access even if they are presented in a purely visual task. Such a proposal is plausible given the strong evidence that 
subjects often cannot avoid interference from visually presented words (e.g. Stroop, 1935; Dyer, 1973). Thus, by adopting this proposal, the difference between letters and words is compatible with the memory access hypothesis. In any case, the main point is that word processing does demand some ability related to reading while letter processing does not always demand such an ability.

Other findings also are available that bolster our conclusion that word processing abilities, but not letter processing abilities, are important for reading. For example, in a study contrasting fast and slow college readers, Graesser, Hoffman, \& Clark (1980) found that the largest part of the total reading time difference between the two groups was due to word processing. There is also an older study of paper and pencil tasks by Holmes (1954) with similar conclusions. Thus, there appears to be a reassuring convergence over the limited set of studies that have focused on this question.

The results obtained here do indicate that individual differences in the speed of retrieval of a word's semantic associate are wide enough to influence individual differences in reading. The ability to perform well in tasks that involve the manipulation of meaning. such as the semantic categorization task, was related both to reading speed and to reading comprehension. While correlations between comprehension tasks and reading are not intuitively surprising. they have proven difficult to find in other investigations (e.g.. Frederiksen, 1980; Stanovich, 1980).

\section{Conclusions}

Three facts led us to conclude that reading speed and comprehension should be treated as distinct abilities rather than being combined into a single reading score. First, reading comprehension ability is highly related to listening comprehension ability. No similar relationship was found between reading speed and listening.
Second, reading speed is more related to the elementary information processing tasks than is reading comprehension. Third, and perhaps most important, the two measures are not closely related if the comprehension tests are not speeded (Blommers \& Lindquist, 1944). Each of these results would go unnoticed if one used a composite reading measure.

Our results also indicate that there are separate, though correlated, dimensions of ability for performing the lexical and syntactic-semantic components of reading. This does not mean that the different processes are necessarily executed sequentially. We address neither the theoretical (e.g., McClelland, 1979) nor empirical studies (e.g., Marcel, 1983) that argue for some semantic processing before the completion of lexical processing. Our work does indicate that individuals vary separately in their abilities to execute each process.

\section{APPENDIX A}

\section{Stimulas Materials for Information Processing Tasks}

\section{Stimuli in Search and Span Tasks}

Letters: a, b, c, d, e, f, g, h, j, k, I. m, n. $o, p, r, s, t, u, v, w, x, y, z$.

Words: lion, seat, time, oven, iron, beer, tile, dish, wall, foil, barn, club, suit, base. coat, salt, sail, tent, ring, hand, home. bark, body, pipe.

\section{Stimuli in Matching Tasks}

Letters: a, b, c, d, e, j, 1, m, n, o, p. r, s, t. $w, x$.

Words: sink, fake, wink, fare, date, dice, gate, dine, damp, galc, ramp, game. fecd, rope, weed, role, buck, nose, tuck, note, cent, race, dent, rare, sore, mile, tore. mine, bake, wine, wake. wise, show, leaf. slow, leap, shot, harm, slot, harp, slat. care, spat, cart, shed, clap, sled, claw, shop, bark, slop, barn, slur, heal, spur. 
hear, swap, form, slap, fork. ship, wind, slip. wing.

\section{Stimuli in the Lexical Decision Task}

These stimuli were kindly provided by David Meyer.

Associated words: king-queen, boyman, butter-bread, nail-hammer, avenuestreet, baby-infant, lock-key, table-chair, peace-war, cat-dog, earth-ground. sister-brother, pin-needle, salt-pepper. carpet-rug, cup-saucer.

Nonassociated words: uncle-silk. trainheat, mind-cabbage, meat-home, woolcity, apple-stream, justice-hand, seedjar, glass-dirt, oil-flower, church-doctor. grass-lamb. window-spool, scissors-insect, plant-bath, waltz-bug.

Word-nonwords: thread-yine, tigernong. eye-voon, moth-zock, bed-rair, moon-shief, cotton-bisic, river-vall. lion-fuass, stove-namb. cracker-erter. soap-pabing. thief-huver, army-wegaring, door-strink, fruit-tocan, shoerapger, web-jilinue, star-phalcle. lawzal. night-joth, sea-vut, dime-cleep, mouse-ogtuce, song-strant, grapes-goe. dance-truit, injury-flove. crown-sutmy, flag-gneat, animal-breen, lamp-eal.

Nomuord-words: heg-yard, fotsencandy, firch-adult, nool-music, listractleal, korse-officer, enpel-cup. morkbagesoldier, yold-mountain, shirser-foot, kipy-health, jad-knife, loitel-plane. globble-sickness, gow-lettuce, katmyfood. poft-hair, ludge-blossom, fup-dish, crisow-steak, wimer-cheese, udy-wine, hanwake-whistle, eaple-town, purchfox, pheese-spider, tusier-school. kuread-water. fleep-stem, rinder-pill. gloet-toast, roise-chalk.

Vonword-nonwords: reater-blar, dubter-voap. dake-telt. jind-vake, srowglain, rast-selt. plue-fiok, lail-keat, glatvack, Lill-woot, daltz-nitvy, jeal-tiew. mitor-stread, poy-jasom. speet-oye, stroom-dound, bither-bance, nour-oit. ded-lome. fough-ovigion. lurse-jarent,

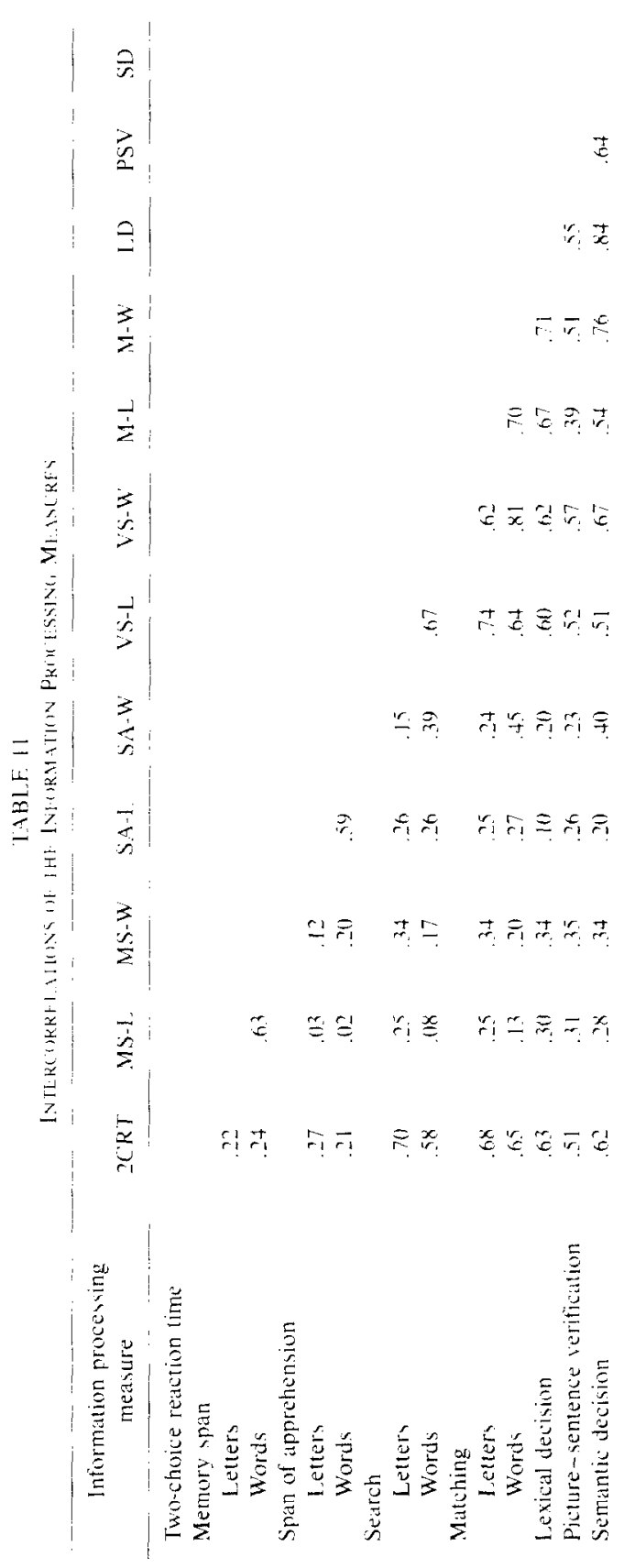




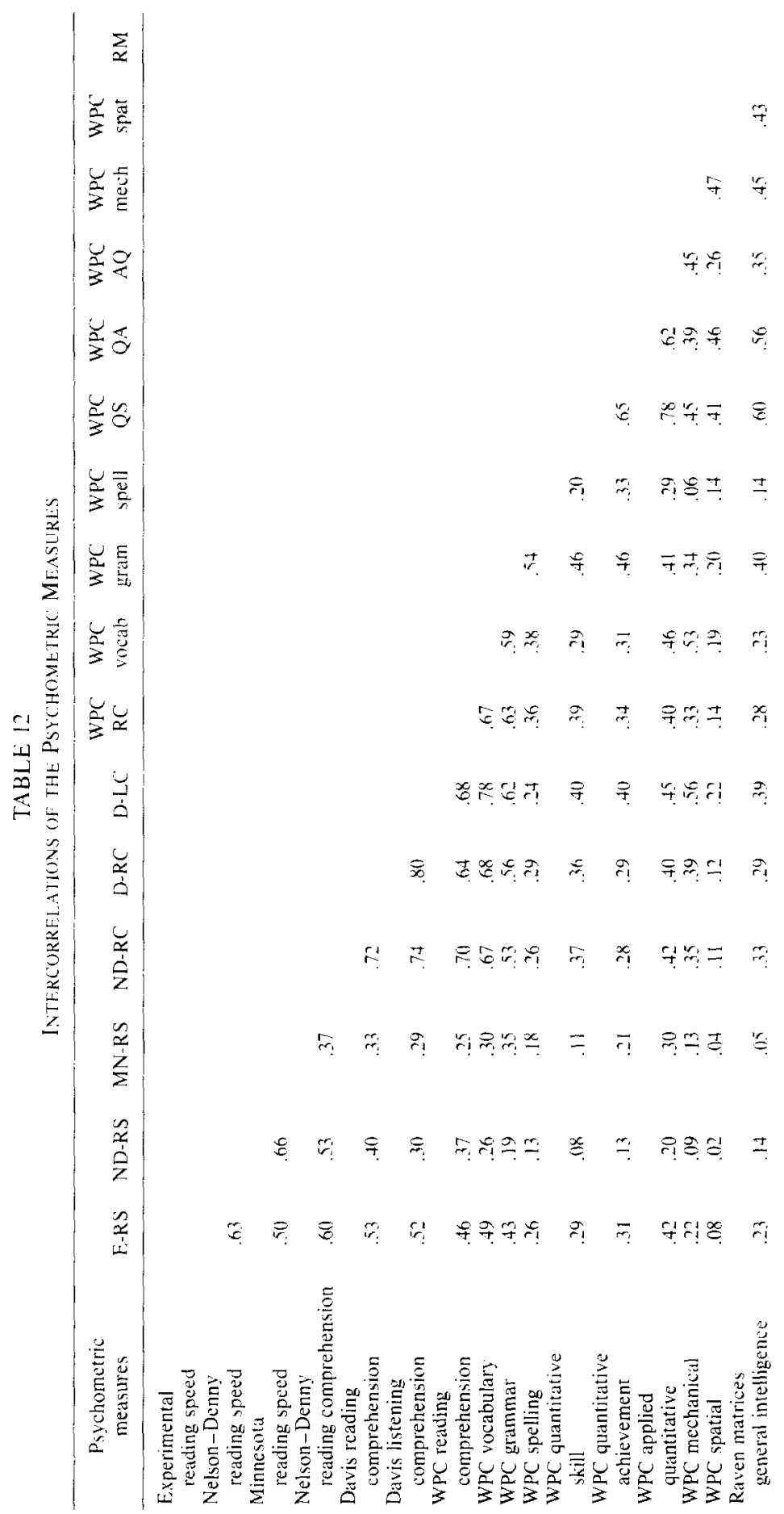




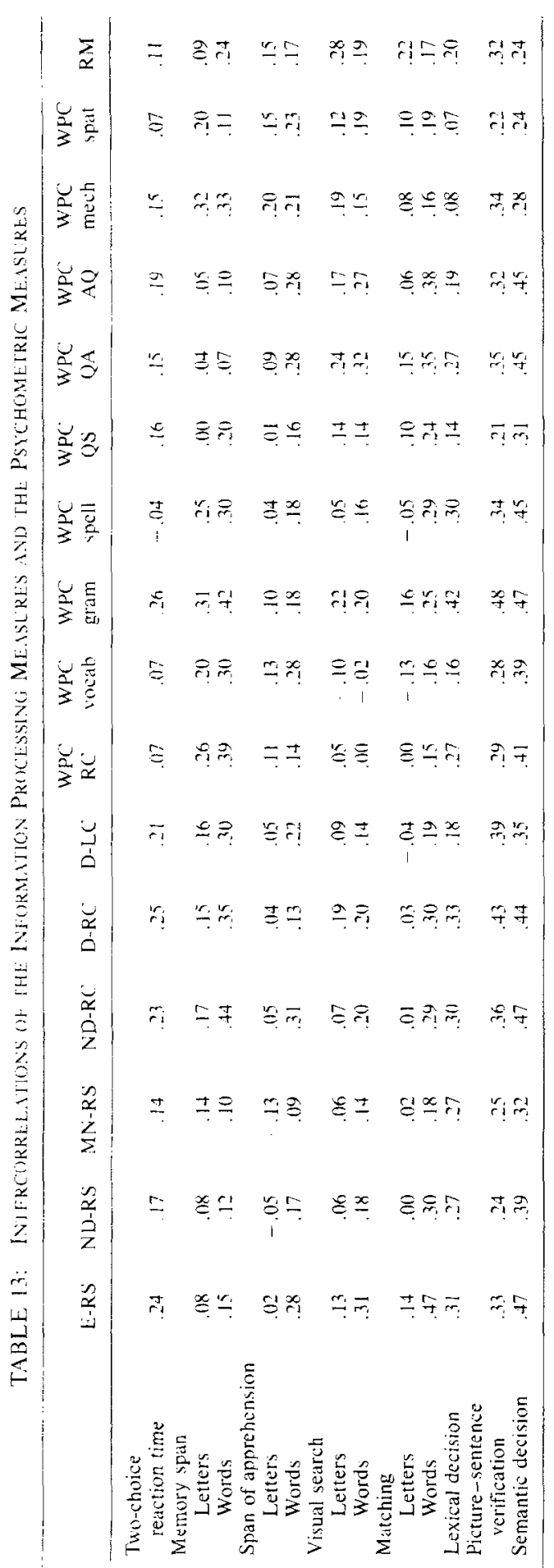

kog-glem, ralt-pleam, jeow-glat, veetain-strapes, ceal-krow, ralt-lanyon, selt-prug, dood-phife, meb-shair, viglegeed, pirlow-greal.

\section{Stimuli in the Semantic Decision Task}

True sentences: A Chevrolet is a Chevrolet. A Corvette is a car. A Pontiac is a vehicle. Brandy is brandy. Whiskey is alcohol. Champagne is a beverage. A Bulldog is a Bulldog. A Collie is a dog. A Terrier is a pet. Beef is heef. Pork is meat. Veal is food. A Private is a Private. A Lieutenant is a soldier. A Corporal is a person. A Maple is a Maple. A Cedar is a tree. An Elm is a plant. Christmas is Christmas. Thanksgiving is a holiday. Easter is a day. A novel is a novel. A dictionary is a book. A Bible is reading material. An emerald is an emerald. A diamond is a jewel. $\Lambda$ ruby is a stone. Football is football. Baseball is a sport. Golf is an activity. A cobra is a cobra. A copperhead is a snake. A python is a reptile. Coca-Cola is Coca-Cola. $7 \mathrm{Up}$ is a soft drink. Sprite is a liquid. Halibut is halibut. Salmon is a fish. Smelt is a seafood. A gorilla is a gorilla. A chimpanzee is a primate. An orangutang is an ape. $A$ canary is a canary. A sparrow is a bird. A robin is an animal. A father is a father. An uncle is a relative. A grandfather is a male. Princeton is Princeton. Oxford is a University. Yale is a school. Calculus is calculus. Trigonometry is math. Algebra is a school subject. A pistol is a pistol. A revolver is a gun. A rifle is a weapon. A mansion is a mansion. A cottage is a house. A bungalow is a building.

False sentences: Toyota is a cardigan. Datsun is a sweater. A Ford is a clothing. A poodle is a Boston cream. An Irish setter is a pie. A Laborador is a dessert. Beer is a black widow. Vodka is a spider. Gin is an insect. Chicken is the Atlantic. Lamb is an ocean. Ham is water. A Sergeant is salt. A Captain is a spice. $A$ Major is a seasoning. A Dogwood is a canoe. An alder is a boat. A fir is transportation. Memorial Day is cheddar. The 4th of July is a cheese. Labor 
Day is a milk product. A biography is Longfellow. A paperback is a poet. An encyclopedia is a writer. A sapphire is a minister. A pearl is a clergyman. An opal is a profession. Flounder is a clarinet. Tuna is a wind instrument. Cod is a musical instrument. Volleyball is a toe. Tennis is a part of a foot. Soccer is a part of a body. A cannon is a cantaloupe. A shotgun is a melon. An automatic is a fruit. Root Beer is a penny. Dr. Pepper is a coin. Orange Crush is money. Geometry is a loafer. Arithmetic is a show. Statistics is footwear. A blue jay is a knife. A crow is silverware. A finch is a utensil. A cabin is June. An adobe is a month. A hut is a unit of time. Harvard is butane. Cambridge is a gas. Stanford is a type of fuel. A brother is iron. $A$ nephew is metal. A son is a mineral. A rattler is Mt. Rainier. A viper is a volcano. Boa is an earth formation. Monkey is aspirin. A Gibbon is a medicine. A Rhesus is a drug.

\section{Appendix B}

\section{Intercorrelations for All Measures}

Three tables are included which summarize all of the relationships among the psychometric and information processing measures. For convenience, Table 11 presents the correlations for just the 12 information processing measures. Table 12 presents the correlations for just the 16 psychometric measures, and Table 13 presents the $12 \times 16$ matrix of the intercorrelations between the psychometric and information processing measures. All relationships are Pearson produc1-moment correlation coefficients based on the 67 subjects with complete data on all measures. All correlation coefficients are positive for positive relationships to reduce confusion in their interpretation.

\section{REFERENCES}

Anderson, J. R., \& Bowlk. G. H. (1973). Human (1,)sociative memory. Washington. D.C.: Winston.

Bentler, P. M. (1980). Mulivariate analysis with latent variables: Causal modeling. Ammal Review of Psychology, 31, 419-456.
Bentliak, P.. \& BONETT. D. (1980). Significance 1esta and goodness of fit in the analysis of covariance structures. Psychological Bulletin, 88. 588-606.

Bishop. Y., Fifnberg, S. \& Hollani). P. (1975). Dis crete multivariate analysis: Theory and practice Cambridge, Mass.: MIT Press.

BIOMMERS. P. \& LINDQUIST. F. F. (1944). Rate of comprehension of reading: Its measurement and its relation to comprehension. Jomal of Cideca tional Psychology, 35. 449-473.

CAltrt.t, R. (1977). Assessment of independent reading skills: Basic research and practical implications. In A. Reber and D. Scarborough (Eds.l. Fonctad a prychology of réciling. Hillsdile. N.J. Frlbaum

CAmpbl:1.. D. T., \& Fiskl. D. W. (1959). Convergent and discriminant validation by the mutitrait multimethod matrix. Psychological Bullotin, 82. $45-73$.

CARPlivtlik, P. A.. \& Just. M. A. 119751 . Sentence comprehension: A psycholinguistic processing model of verification. Psuchological Rericus, 82. $45-73$.

CARK. T. H. (1981). Building theories of reading ability: On the relation between individuat differences in cognitive skills and reading comprehension. Cognition, 9, 73-114.

CаккоL. . J. B. \& MAxwFt.1. S. E. (1979). Individual differences in cognitive abilities. Ammal Rericu of Psychology, 30. 603-640.

Catri:1... J. M. (1947). Ueber die Zeil der Erkennung und Benennung von Schriftzeichen. Bildern. und Farben. In A. T. Poffenberger (Ed.) James Maken Cattell Man of sione York. Pa: Soience Press. Reprinted in translation from Phile.. sephische Studien, 1885, 2, 635-650.

Cavanacih, J. P. (1972). Relation between the imme diate memory span and the memory search rate Parcholugical Review, 79, 525-530.

CLARK. H. H.. \& CHASE. W. G. (1972). On the proce's of compiring sentences against pictures. C $(x, h i-$ in' Pruchology, 3, 472-517.

Colins. A. M. \& Q[ILliAN. M. R. (1969). Retrieval time from semantic memory. Jommal of Viobal Learning and Verhal Bchavior, 8, 240-247.

DAvis. F. B.. \& Davis. C. C. (1962). Devis reading test. New York: Psycholugical Corp.

Donaldoson. G. (1983). Confirmatory factor analysis nodels of information processing stages: An alternative to difference scores. Puychological $B_{t d}$ lotin. 94, 143-151.

DyIR. F. V. (1973). The Stroop phenomena and its use in the study of perceptual, cognitive, and response processes. Memory and Cognition. 1973. 1. 106-120.

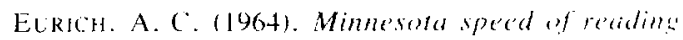
1ess. Minneapolis: Lniv. of Minnesola Press.

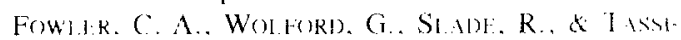


NARY. L. (1981). Lexical access with and without awareness. Jotmat of Experimental Psycholegy: General, 110, 341-362.

FRIEDERIKSEN. J. R. (1978). Assessment of perceptual. decoding, and lexical skills and their relation to reading proficiency. In A. M. Lesgold, J. W. Pellegrino, S. D. Fokkema, and R. Glaser (Eds.), Cognitive psychology and instruction. New York: Plenum.

FREDERIKSEN, J, R. (1980). Component skills in reading: Measurement of individual differences through chronometric analysis. In R. Snow, P. Federico, and W. Montague (Eds.), Aptitude. learning and instraction: Cognitive process analrits of aptitude $(\mathrm{Vo})$. 1). Hillsdale, N.I : Frlbaum.

FRFIDLRIKSEN. J. R. (1982). A componential model of reading skills and their interrelations. In R. J. Sternberg (Ed.). Adrances in the psychology of haman intelligence. Hillsdale. N.J.: Erlbaum.

Ghimimav. R. E.. Woodward. J. A., \& Bentry, J. (1982). Individual differences in verbal memory performance: A test of alternative informationprocessing models. Jommal of Experimenal Psychelosy: General 111, 109-134.

Gibsos. E. I. \& LtVIN. H. (1975). The psychologl of reading. Cambridge. Mass.: The MIT Press.

Gratsitr, A. C., Holfman. N., \& Clakk, L. F. (1980). Structural components of reading time.

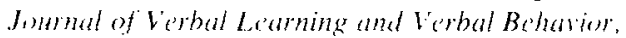
$19,135-151$.

Hol vis, J. A. (1954). Faclors underlying major reading disabilities at the college level. Genetic Psychology Monographs, 49. 3-95.

Hivt. F. (1978). Mechanies of verbal ability. Prochological Revitu', 1978, 85, 109-130.

He vT, t.. Frost, N.. \& Lunvfhorg. C. (1973). Individual differences in cognition. In E. Bower (Ed.). The psychologe of learning and motivation: Adrances in resederth and therery (Vol. 7). New York: Academic Press.

Hivt, E., L L nveborg, C. \& L.t.wis, J. (1975). What does it mean to be high verbal? Cognitive Psycheresus, 7, 194-227.

Huvi. E., MeKle, C., \& Yantis, S. (1978). Comparisun of antomated processing paradigms. Paper presented at the annual meeting of the Psychonomic Sociely, San Antonio, Tex.

JA ksov. M. D. (1980). Further evidence for at relationship between memory aceess and reading ability. Jom of Verbal Leaming and Verbal Behavior, 19, 683-694.

JA(KSoN. M. D. \& MCCIFILAVI), J. L. (1975). Sensory and cognitive determinants of reading speed. Journal of Verbal Leaming and Verbal Behation. 14. $565-574$.

Jackson, M. D., \& M(Clelland, J. L. (1979). Processing determinants of reading speed. fonmat af Exprimental Psichology: Goneral. 108. 151181 .
JORF.SKOG. K. G. (1974). Analyzing psychological data by structural analysis of covariance matrices. In D. H. Krantz, R. C. Atkinson, R. D. Luce, and P. Suppes (Eds.), Contemporary developments in mathematical psychology (Vol. 11). San Francisco: Freeman.

JORFSKOG, K. G., \& SÖrbOM. D. (1978). LISREI. IV. Analysis of linear structural relationships by the methed of maximum likelihood. Chicago: National Education Services.

KAIL. L. \& WKKLLND, D. (1972). Letler scanning rate for good and poor readers in grades two and six. Journal of Edacational Psychology, 63, 363367.

I ANSMAN, M. DONALDSON, G., HLNT, E., \& Yantis, S. (1982). Ability factors and cognitive processes. Intelligence, 6, 347-386.

LYON. D. R. (1977). Individual differences in serial recall: A matter of mnemonics? Cugnitive Psybolog! 9, 403-411.

MARCFI, A. J. (1983). Conscious and unconscious perception: Experiments on visual masking and word recognition. Cognitive Psychology, 15, $197-$ 237.

MCCLELAANI), J. L., (1979). On the time relations of mental processes: An examination of systems of processes in cascade. Prychological Review, 86, $287-330$.

MCCONKIF, G. W. RAYNER, K., \& WHASON, S. J. (1973). Experimental manipulation of reading strategies. Jommal of Educational Psychology. $65,1-8$.

Mfyer, D. E., Schvanevildot, R. W., \& Rumpy. M. G. (1972. November). Activation of levicat memory. Paper presented at the annual meeting of the Psychonomic Society, St. Louis, Mo.

Neison, M. J., \& Denny, E. C. (1960). The NelsronDenny reading test. Boston: Houghton Mifflin.

Pertetri. C. A. (1984). Reading ability, In R. J. Sternherg (Ed.). Homan abilities: An information pro. cessing approach. San Francisco: Freeman.

PerfftTI. C.. \& LFsgold. A. (1978). Discourse comprehension and sources of individual differences. In M. Just and P. Carpenter (Eds.), Cognitive procosses in comprehension. Hillsdale, N.J.: Erlbaum.

POSNeR, M. I., \& MITCHFi.l. K. F. (196)). Chronometric analysis of classification. Psychelesical Revie'w, 74, 392-409.

Raviv. J. C. (1965). Adranced progressite matrices, Sets I and II. London: Lewis.

RLBENSTLIN, H. LlWWIS. S. S. \& RLBBENTEIN, M. A. (1971). Evidence for phonemic recoding in visual word recognition. Joumal of l'erbal Learning and Verbal Behavior, 10, 645-657.

SMITH, E. E. \& \& Spothr, K. (1974). The perception of printed English: A theoretical perspective. In B. H. Kantowitz (Ed.), Haman information procersing. Hillsdale, N.J.: Erlbaum. 
Stanovich, K. (1980). Toward an interactive compensatory model of individual differences in the development of reading fluency. Reading Research Quarterly, 16, 32-71.

STERnBerg, S. (1966). High speed scanning in human memory. Science (Washingtom, B.C.) 153, 652654.

Sternberg, S., \& Scarborough. D. L. (1969, July). Parallel testing of stimuli in vistual search. Paper presented at the international symposium on $\mathrm{Vi}$ sual Information Processing and Control of Motor Activity, Sofia, Bulgaria.

STICHT, T. G. (1972). Learning by listening. In J. B Carroll \& R. O. Freedle (Eds.), Language comprehension and the acquisition of knowledge. Washington D.C.: Winston.
Stroop, J. R. (1935). Studies of interference in serial verbal reactions. Journal of Experimental $P s y$ chology, 18, 643-662.

Technical manual: Washington pre-college test battery. (1977). Seattle: University of Washington Assessment Center.

Theios, J., Smith, P., Haviland, S.. Traupmann, J. \& Mor, M. (1973). Memory scanning as a serial self-terminating process. Joum of Experimental Psychology, 97, 323-336.

(Received September 29, 1983)

(Revision received April 4, 1984) 